\title{
Effects of Laparoscopic Cholecystectomy on Mucin1 and Cholesterol Ester Transfer Protein Status in Bangladeshi patients with Cholelithiasis
}

\author{
Md Abdul Mobin Choudhury ${ }^{1}$, A.S.M Giasuddin ${ }^{2 *}$, Khadiza Akhter Jhuma ${ }^{3}$, A.M. Mujibul Haq ${ }^{4}$ \\ ${ }^{1}$ Department of Surgery, Medical College for Women \& Hospital, Dhaka, Bangladesh \\ ${ }^{2}$ Department of Biochemistry and Immunology, Medical Research Unit (MRU), Dhaka, Bangladesh \\ ${ }^{3}$ Department of Biochemistry, Medical College for Women \& Hospital, Dhaka, Bangladesh \\ ${ }^{4}$ Department of Medicine, Medical College for Women \& Hospital, Dhaka, Bangladesh
}

*Corresponding author: ASM Giasuddin, Department of Biochemistry and Immunology, Medical Research Unit (MRU), Dhaka, Bangladesh, Tel: 880-2-58953939; Email: asmgias@hotmail.com

Received date: February 15, 2018; Accepted date: March 26, 2018; Published date: March 30, 2018

Copyright: (C) 2018 Giasuddin ASM. This is an open-access article distributed under the terms of the creative commons attribution license, which permits unrestricted use, distribution, and reproduction in any medium, provided the original author and source are credited.

\begin{abstract}
Objective: Although it was reported that cholecystectomy had profound impact on lipid profile and lipoprotein (a) status, no studies were reported on Mucin1 and cholesterol ester transfer protein (CETP) in Bangladeshi patients with cholelithiasis i.e. gallstone disease (GD). The present study was done about effects of laparoscopic cholecystectomy on Mucin1 and CETP status in Bangladeshi patients with cholelithiasis.

Patients \& Methods: Forty-four adult GD patients with cholelithiasis and 30 normal controls (NC) subjects were included in the study. The blood was taken from fasting patients before cholecystectomy (Serum- $I^{\circ}$ ), gall bladder bile during cholecystectomy $\left(\right.$ Bile- $\mathrm{I}^{\circ}$ ) and blood again after 2-3 months at follow-up (Serum- $\mathrm{I}^{\circ}$ ) and from fasting NC subjects. Mucin1 and CETP levels were quantified in serum and bile by enzyme immunoassay (EIA) method using commercially available research kits. The results were compared by appropriate statistical tests using SPSS program.

Results: Serum levels of both Mucin1 and CETP were increased in $\mathrm{Pt}-\mathrm{I}^{\circ}(\mathrm{S})$ compared to $\mathrm{NC}-\mathrm{I}^{\circ}(\mathrm{S})$ which were reduced after cholecystectomy in Pts- $I^{\circ}(S)$. However, serum CETP mean level in Pts- $I^{\circ}(S)$ was not significantly higher than $\mathrm{NC}-\mathrm{I}^{\circ}(\mathrm{S})$. The Mucin1 and CETP levels in patients bile, i.e. Pt- $\mathrm{I}^{\circ}(\mathrm{B})$, were lower compared to serum levels before, $\mathrm{Pt}-\mathrm{I}^{\circ}(\mathrm{S})$, and after, $\left(\mathrm{Pt}-\mathrm{II}^{\circ}(\mathrm{S})\right.$, cholecystectomy [Mucin1 $(\mathrm{ng} / \mathrm{ml}):$ Pts- $\mathrm{I}^{\circ}(\mathrm{S}): 10.77 \pm 2.93$, Pts- $\mathrm{I}^{\circ}(\mathrm{B}): 1.29$ \pm 1.21 , Pts $I^{\circ}(S): 6.67 \pm 2.03, \mathrm{NCs}\left(I^{\circ}\right): 4.63 \pm 0.53 ; \operatorname{CETP}(\mu \mathrm{g} / \mathrm{ml}):$ Pts $-\mathrm{I}^{\circ}(\mathrm{S}): 11.47 \pm 5.04$, Pts- $\mathrm{I}^{\circ}(\mathrm{B}): 1.16 \pm 1.19$, Pts-II $(\mathrm{S}): 9.41 \pm 2.42, \mathrm{NCs}\left(I^{\circ}\right): 9.57 \pm 3.63$ ] . A significantly large proportion of patients had higher levels of Mucin1, but large number of patients had CETP levels within the normal range in Pt-I $\mathrm{I}^{\circ}(\mathrm{S})$. Interestingly, this was changed after cholecystectomy that significant proportion of patients had higher CETP levels in $\mathrm{Pt}-\mathrm{II}^{\circ}(\mathrm{S})$.

Conclusions: Alterations in serum Mucin1 and CETP status were significant but complex and laparoscopic cholecystectomy had significant impact indicating an important function of gallbladder relevant to their metabolism. Further studies are needed on prevalence and frequency of metabolic syndrome, insulin resistance, cytokines and other relevant parameters in Bangladeshi patients with GD i.e. cholelithiasis.
\end{abstract}

Keywords: Cholelithiasis; Gallstone disease; Mucin1; CETP; Laparoscopic cholecystectomy

\section{Introduction}

The prevalence of gallbladder disease has advanced with the use of ultrasound surveys as opposed to previous studies based on clinical or necropsy evidence $[1,2]$. Of the gallbladder diseases, cholelithiasis i.e. gallstone disease (GD) is prevalent in about $10-15 \%$ of adults in the developed countries and one of the most common of all digestive disorders requiring hospital admissions [2-4]. Cholesterol gallstones account for $80-90 \%$ of all gallstones found during cholecystectomy [5]. Cholesterol gallstones are primarily made up of cholesterol crystals (70\%) which are held together in an organic matrix of glycoproteins, calcium salts and bile pigments [6]. The etiology of cholesterol gallstones is multi-factorial, with interaction of genetic and/or environmental factors [7]. Some features such as genetics, advancing age and female gender cannot be modified, whereas others such as diet, physical activity, rapid weight loss and obesity are modifiable [2].

The first step in the formation of gallstones is the secretion of bile supersaturated with cholesterol by the liver. The second step in gallstone formation is crystallization. The precipitation of cholesterol crystals initiates the formation of gallstones. When the gallbladder bile becomes abnormally supersaturated, inhibitors of crystallization are also important in the initiation of nucleation and crystal formation. The promoters and inhibitors are mostly proteins such as mucous glycoproteins. The growth of the crystal to macroscopic stones is further facilitated by the gallbladder mucus $[7,8]$. It soon became clear that other factors including nucleation of cholesterol crystal, binding together of these crystals with Mucin and hypomotility of the gallbladder played equally important roles in gallstone formation [3]. Controversy exists as to whether pro- or anti-nucleating factors are responsible for the development of cholelithiasis particularly cholesterol gallstones in humans. Experimental studies in animals and 
humans indicated that gallbladder Mucin, a high molecular weight glycoprotein secreted by the gallbladder epithelium, is important for the initiation of gallstone formation [9]. The initial stage of gallstone formation, nucleation of cholesterol monohydrate crystals, occurs in mucus gel adherent to the gallbladder epithelium $[9,10]$. Aspirin, in doses that suppress Mucin hyper secretion, prevents cholesterol crystal nucleation and stone formation while not altering the super saturation of gallbladder bile with cholesterol [9,11]. Moreover, a mucin-bilirubin complex was reported to be present in the nonlipid matrix at the centre of cholesterol gallstones having a pigment composition like biliary sludge. These observations taken together suggest that gallbladder sludge consisting of mucus and bile pigments may serve as the core for gallstone development in man [12].

Exogenous, endogenous, intracellular-cholesterol transport and reverse-cholesterol transport are the major pathways of lipoprotein metabolism. These pathways are important and complex relevant to lipids and lipoproteins metabolism. The function of the reversecholesterol transport pathway is to remove excess cellular cholesterol from peripheral cells and return it to the liver for excretion and largely mediated by high density lipoprotein (HDL). Lecithin cholesterol acyltransferase (LCAT) which esterifies cholesterol on HDL, plays an important role in reverse-cholesterol transport. Cholesterol ester transfer protein (CETP) also plays a key role in this pathway because significant fraction of cholesterol that is removed from cells by HDL is transferred as cholesterol esters onto low-density lipoprotein (LDL) by CETP and eventually removed from the circulation by hepatic LDLreceptor [13-15]. In recent times cholesterol gallstone disease is considered as a metabolic syndrome which correlates with lipid abnormalities, particularly low HDL-cholesterol, hypertriglyceridemia and high homocysteine levels [16-21].

Considering these important observations and parameters and complex pathways, we have investigated effects of laparoscopic cholecystectomy on lipid profile, lipoprotein (a) [Lp(a)] status, Mucin1, CETP and Apolipoproteins (ApoA1, ApoB100, ApoE) levels in Bangladeshi patients with GD i.e. cholelithiasis. The results on lipid profile and $\operatorname{Lp}(\mathrm{a})$ status were published previously $[22,23]$. Therefore, the results on serum Mucin1 and CETP levels are reported in the present communication.

\section{Patients and Methods}

The patients and methods were the same as described previously in our earlier publications [22,23]. Forty-four adult patients (Gender: 8 males, 36 females; Age range: $25-65$ years, mean age \pm SD: $45.5 \pm 12.2$ years) with cholelithiasis i.e. GD and 30 healthy adult normal controls (Gender: 12 males, 18 females; Age range: 28-60 years; Mean age \pm SD: $42.5+10.5$ years) were included in this case-control prospective interventional study. The patients with GD were diagnosed as having cholelithiasis according to standard clinical and laboratory criteria as practiced in hospitals and patients not fulfilling the criteria for our study were excluded [22,23]. After obtaining consent, patient's demographic details and clinical findings such as pain (severity, duration, location), Murphy's sign, ultrasonogram (USG), etc were recorded as per 'PROFORMA' at diagnosis. The fasting blood samples were taken at diagnosis before cholecystectomy and conducted routine laboratory tests. The serum separated was aliquoted and stored frozen at $-300^{\circ} \mathrm{C}$ to $-80^{\circ} \mathrm{C}$ as first degree serum sample $\left(\mathrm{I}^{\circ}\right)$. At the time of cholecystectomy, gall bladder bile was also collected from the same patient, centrifuged, aliquoted and stored frozen at $-300^{\circ} \mathrm{C}$ to $-80^{\circ} \mathrm{C}$ as first degree bile sample $\left(\mathrm{I}^{\circ}\right)$. After Cholecystectomy, treatments/ medications were given as required for the patients. After 2-3 months at follow-up, fasting blood samples were taken again from the same patient, serum separated, aliquoted and stored frozen at $-300 \mathrm{C}$ to $-80^{\circ} \mathrm{C}$ as second degree serum samples $\left(\mathrm{II}^{\circ}\right)$ until analyzed for the special laboratory parameters, i.e. lipid profile (i.e. TG, TC, HDL-C, LDL-C), Lp(a), Mucin1, CETP and Apolipoproteins (ApoA1, ApoB100, ApoE) levels. All quantitative estimations in serum and bile were made by standard medical laboratory methods for lipid profile and $\mathrm{Lp}(\mathrm{a})$ using standard diagnostics kits from internationally reputed companies and LDL-C calculated by Friedwald formula [13-15]. The Mucin-1 and CEPT were quantitatively estimated by using Human Mucin-1 (MUC1) ELISA kit (Cat No YH B2055 Hu) and Human Cholesterol Ester Transfer Protein (CETP) ELISA kit (Cat No YH B0694 Hu) respectively from Shanghai Yehnua Biological Technology Co Ltd, China. The results of laboratory analyses in biological specimens of patients $\left(\mathrm{I}^{\circ}, \mathrm{II}^{\circ}\right)$ and controls (NC) were compared statistically by ANOVA, Student's t-test and Chi-squared ( $\left.\chi^{2}\right)$ test using SPSS program in computer [24]. The results of our studies on lipid profile i.e. TG, TC, HDL-C, LDL-C and Lp(a) were reported previously $[22,23]$. In the present article, the results on Mucin 1 and CETP status and effects of Laparoscopic cholecystectomy on them in our Bangladeshi Patients with GD i.e. Cholelithiasis are reported.

\section{Results}

The results on serum Mucin1 and CETP levels in cholelithiasis are stated in Table 1 and Table 2. Serum levels of both Mucin1 and CETP were increased in $\mathrm{Pt}-\mathrm{I}^{\circ}(\mathrm{S})$ compared to $\mathrm{NC}-\mathrm{I}^{\circ}(\mathrm{S})$ which were reduced after cholecystectomy in Pts- $\mathrm{II}^{\circ}(\mathrm{S})$. However, serum CETP mean level in $\mathrm{Pts}-\mathrm{I}^{\circ}(\mathrm{S})$ was not significantly higher than $\mathrm{NC}-\mathrm{I}^{\circ}(\mathrm{S})$. The Mucin1 and CETP levels in patient's bile, i.e. $\mathrm{Pt}-\mathrm{I}^{\circ}(\mathrm{B})$, were lower compared to serum levels before, $\mathrm{Pt}-\mathrm{I}^{\circ}(\mathrm{S})$, and after, $\left(\mathrm{Pt}-\mathrm{II}^{\circ}(\mathrm{S})\right.$, cholecystectomy (Table 1). A significantly larger proportion of patients had higher levels of Mucin1, but larger number of patients had CETP levels within the normal range in $\mathrm{Pt}-\mathrm{I}^{\circ}(\mathrm{S})$. Interestingly, this was changed after cholecystectomy that significant proportion of patients had higher CETP levels in $\mathrm{Pt}_{-} \mathrm{II}^{\circ}(\mathrm{S})$ (Table 2).

\begin{tabular}{|c|c|c|c|c|c|c|c|c|}
\hline \multirow[t]{3}{*}{ Groups compared } & \multicolumn{4}{|c|}{ Mucin $1(\mathrm{ng} / \mathrm{ml})^{*}$} & \multicolumn{4}{|c|}{ CETP $(\mu \mathrm{g} / \mathrm{ml})^{*}$} \\
\hline & \multicolumn{2}{|l|}{ Pts } & \multicolumn{2}{|l|}{ NCs } & \multicolumn{2}{|l|}{ Pts } & \multicolumn{2}{|l|}{ NCs } \\
\hline & Serum $\left(I^{\circ}\right)$ & Bile $\left(1^{\circ}\right)$ & Serum $\left(\mathrm{II}^{\circ}\right)$ & Serum $\left(1^{\circ}\right)$ & Serum $\left(1^{\circ}\right)$ & Bile $\left(1^{\circ}\right)$ & Serum $\left(11^{\circ}\right)$ & Serum (I) \\
\hline$N$ & 55 & 40 & 45 & 40 & 55 & 40 & 45 & 40 \\
\hline Obs Range & $4.39-15.31$ & $0.21-4.38$ & $2.85-10.21$ & $3.73-5.89$ & $3.53-18.91$ & $0.23-4.96$ & $3.52-13.14$ & $5.18-20.12$ \\
\hline Mean \pm SD & $10.7 \pm 2.93$ & $1.29 \pm 1.20$ & $6.66 \pm 2.03$ & $4.63 \pm 0.53$ & $11.47 \pm 5.04$ & $1.16 \pm 1.19$ & $9.40 \pm 2.42$ & $9.57 \pm 3.62$ \\
\hline
\end{tabular}


Citation: Choudhury MAM, Giasuddin ASM, Jhuma KA, Haq AMM (2018) Effects of Laparoscopic Cholecystectomy on Mucin1 and Cholesterol Ester Transfer Protein Status in Bangladeshi patients with Cholelithiasis. J Metabolic Synd 7: 240. doi:10.4172/2167-0943.1000240

Page 3 of 5

\begin{tabular}{|c|c|c|c|c|c|c|c|c|}
\hline Std Error(SEM) & 0.4 & 0.19 & 0.3 & 0.08 & 0.68 & 0.19 & 0.36 & 0.57 \\
\hline $95 \% \mathrm{CIM}$ & $9.97-11.56$ & $0.91-1.68$ & $6.05-7.26$ & $4.68-4.80$ & $10.11-12.84$ & $0.78-1.54$ & $8.68-10.13$ & $8.41-10.72$ \\
\hline ANOVA (NCs-1 ${ }^{\circ}$, Pts- $1^{\circ}, \quad$ Pts- $1^{\circ}(B)$ & \multicolumn{2}{|c|}{$\mathrm{df}(\mathrm{Bg}, \mathrm{Wg}$, Total $)$} & F-ratio & $P$-value* & \multicolumn{2}{|c|}{$\mathrm{df}(\mathrm{Bg}, \mathrm{Wg}$, Total $)$} & F-ratio & $P$-value* \\
\hline & \multicolumn{2}{|l|}{3} & 182.63 & $<0.001$ & \multicolumn{2}{|l|}{3} & 72.36 & $<0.001$ \\
\hline Student's t- test & \multicolumn{2}{|l|}{ t-value } & Df & P-value ${ }^{*}$ & \multicolumn{2}{|l|}{ t-value } & df & P-value* \\
\hline NCs-l $1^{\circ}(\mathrm{S})$ vs Pts-l ${ }^{\circ}(\mathrm{S})$ & \multicolumn{2}{|l|}{-13.06} & 93 & $<0.001$ & \multicolumn{2}{|l|}{-2.04} & 93 & 0.044 \\
\hline NCs-l $1^{\circ}(\mathrm{S})$ vs Pts-l $\mathrm{I}^{\circ}(\mathrm{B})$ & \multicolumn{2}{|l|}{16.08} & 78 & $<0.001$ & \multicolumn{2}{|l|}{13.94} & 78 & $<0.001$ \\
\hline 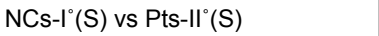 & \multicolumn{2}{|l|}{-6.13} & 83 & $<0.001$ & \multicolumn{2}{|l|}{0.246} & 83 & 0.806 \\
\hline Pts-l ${ }^{\circ}(\mathrm{S})$ vs Pts- $^{\circ}(\mathrm{B})$ & \multicolumn{2}{|l|}{19.27} & 93 & $<0.001$ & \multicolumn{2}{|l|}{12.66} & 93 & $<0.001$ \\
\hline Pts-l $^{\circ}(\mathrm{B})$ vs Pts- $-I^{\circ}(\mathrm{S})$ & \multicolumn{2}{|l|}{-14.61} & 83 & $<0.001$ & \multicolumn{2}{|l|}{-19.54} & 83 & $<0.001$ \\
\hline Pts- $1^{\circ}(\mathrm{S})$ vs Pts-II $(\mathrm{S})$ & \multicolumn{2}{|l|}{7.97} & 98 & $<0.001$ & \multicolumn{2}{|l|}{1042} & 98 & 0.013 \\
\hline
\end{tabular}

Table 1: Mucin1 and CETP levels in patients (Pts) and controls (NCs).

\begin{tabular}{|c|c|c|c|c|c|c|c|c|c|}
\hline \multirow[t]{2}{*}{ Laboratory Parameter } & \multicolumn{9}{|c|}{ Patients (Pts) \& Normal Controls (NCs) ${ }^{*}$} \\
\hline & NCs- $I^{\circ}$ & Serum- $1^{\circ}$ & Total & NCs- $-1^{\circ}$ & Serum- $I^{\circ}$ & Total & $\begin{array}{l}\text { Serum-1 } \\
\text { (Pts) }\end{array}$ & $\begin{array}{l}\text { Serum-II0 } \\
\text { (Pts) }\end{array}$ & Total \\
\hline \multicolumn{10}{|l|}{ Mucin 1 (ng/ml) } \\
\hline$\leq 5.69$ & 36 & 3 & 39 & 36 & 17 & 53 & 3 & 17 & 20 \\
\hline$>5.69$ & 4 & 52 & 56 & 4 & 28 & 32 & 52 & 28 & 80 \\
\hline Total & 40 & 55 & 95 & 40 & 45 & 85 & 55 & 45 & 100 \\
\hline Chi-squared $\left(x^{2}\right)$ test $^{*}$ & \multicolumn{3}{|c|}{$x^{2}=68.40, d f=1, p<0.001$} & \multicolumn{3}{|c|}{$x^{2}=43.24, d f=1, p<0.001$} & \multicolumn{3}{|c|}{$x^{2}=16.16, d f=1, p<0.001$} \\
\hline \multicolumn{10}{|l|}{ CETP $(\mu \mathrm{g} / \mathrm{ml})$} \\
\hline$\leq 16.18$ & 37 & 47 & 84 & 37 & 44 & 81 & 47 & 41 & 88 \\
\hline$>16.18$ & 3 & 8 & 11 & 3 & 1 & 4 & 8 & 4 & 12 \\
\hline Total & 40 & 55 & 95 & 40 & 45 & 85 & 55 & 45 & 100 \\
\hline Chi-squared $(x 2)$ test $^{*}$ & \multicolumn{3}{|c|}{$x^{2}=1.12, d f=1, p=289$} & \multicolumn{3}{|c|}{$x^{2}=1.32, d f=1, p=0.251$} & \multicolumn{3}{|c|}{$x^{2}=0.75, d f=1, p=0.386$} \\
\hline
\end{tabular}

Table 2: Proportion of patients (Pts) with abnormal serum Mucin 1and CETP levels before and after laparoscopic cholecystectomy and their statistical analysis by Chi-squared $(\chi 2)$ test.

\section{Discussion}

Multiple case-control studies, comparing those with gallstone versus those without, have shown that pathogenesis of GD is multi-factorial associated with old age, obesity, specific dietary habit, resistance, pregnancy, ethnicity and genetic background [5,25-28]. It is thought that the GD probably develops from complex interactions among multiple genetic and environmental factors $[5,27,28]$. Recently, it was reported that metabolic syndrome is associated as one of the important components in GD [25,28-30]. GD is a metabolic problem which correlates with lipid abnormalities such as low HDL-cholesterol, hypertriglyceridemia carrying an increased risk of developing stones $[22,23,30]$. More recently, we have reported the lipid abnormalities in our patients with GD earlier in 2016 [22,23]. In the present article, we have reported our study results on Mucin1 and CETP levels in the same patients with GD. This study report is the first of its kind to demonstrate and document abnormal levels of Mucin1 and CEPT in Bangladeshi patients with GD. We found that both Mucin1 and CETP levels were raised in $\mathrm{Pts}^{\circ} \mathrm{I}^{\circ}(\mathrm{S})$ significantly (Table 1$)$. A significantly 
large proportion of patients had higher levels of Mucin1, but large number of patients had CETP levels within the normal range in $\mathrm{Pt}-\mathrm{I}^{\circ}$

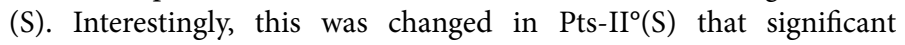
proportion of patients had higher CETP levels after cholecystectomy in Pt-II $(S)$ (Table 2).

The metabolic syndrome is defined by the presence of at least 3 features out of: abdominal obesity, high blood pressure, high fasting glucose, insulin resistance, increased triglyceride and reduced HDL levels $[16,20,21]$. Both the metabolic syndrome and diabetes mellitus are risk factors for GD [25]. Insulin resistance predisposes to cholesterol gallstone formation suggesting altered cholesterol and bile salt metabolism [31,32]. Also, hepatic insulin resistance may act by enhancing hepatic cholesterol secretion, depressing bile salt synthesis and impairing gallbladder motility [33,34]. Bile plays important role in fat/lipid digestion and absorption and gallbladder bile is secreted due to contraction of it and relaxation of sphincter of oddi by various physiological mechanisms [35]. It is quite possible that abnormal Mucin1 and CETP levels are involved in the process of developing metabolic syndrome through dyslipidemia causing impaired gallbladder function, particularly reduced motility. This is probably one the ways which create favorable environment leading to stone formation in the gallbladder. Hence, it is important to investigate the prevalence and extent of metabolic syndrome and its components in our patients with GD i.e. cholelithiasis.

In conclusion, Mucin1 and CETP levels have implications in the process of gallstone formation through dyslipidemia causing possibly metabolic syndrome. It would, therefore, be worthwhile and interesting to conduct further studies along this line in Bangladeshi patients with GD i.e. cholelithiasis soon.

\section{Acknowledgements}

The authors appreciate Mr. TK Datta, Medical Technologist, for laboratory analysis, Mr. SMN Ali for computer composing and Mr. AHM Salman for statistical analysis. The authors gratefully acknowledge the financial support of The Medical and Health Welfare Trust (MHWT), Uttara Model Town, Dhaka-1230, Bangladesh for the research project.

\section{References}

1. Apstein MD Carey MC (1996) Pathogenesis of cholesterol gallstones: a parsimonious hypothesis. Eur J Clin Invest 26: 343-352.

2. Rao PJ, Jarari A, ElAwami H, Patil TN (2012) Lipid profile in bile and serum of cholelithiasis patients-A comparative study. J Basic Med Allied Sci 1: 11- 21.

3. Everhart JE, Khare M, Hill M, Maurer KR (1999) Prevalence and ethnic differences in gallbladder disease in the United States. Gastroenterology 117: 632-639.

4. Sandler RS, Everhart JE, Donowitz M, Adams E, Cronin K, et al. (2002) The burden of selected digestive diseases in the United States. Gastroenterology 122: 1500-1511.

5. Diehl AK (1991) Epidemiology and natural history of gallstone disease. Gastroenterol Clin North Am 20: 1-19.

6. Portineasa P, Moschetta A, Palasciano G (2006) Cholesterol gallstone disease. Lancet 368: 230-239.

7. Amigo L, Zanlungo S, Mendoza H, Miquel JF, Nervi F (1999) Risk factors and pathogenesis of cholesterol gallstones: state of the Art (Editorial). Eur Rev Med Pharmacol Sci 3: 241-246.

8. Avunduk C (2008) Gallstones. In: Manual of Gastroenterology: Diagnosis and Therapy, Fourth Edition; London: Lippincott Williams \& Wilkins.
9. Smith BF (1987) Human gallbladder mucin binds biliary lipids and promotes cholesterol crystal nucleation in model bile. J lipid Res 28: 1088-1097.

10. Womack NA (1971) The development of gallstones. Surg Gyn Obstet 133: 937-945.

11. Lee SP, Carey MC, LaMont JT (1981) Aspirin prevention of cholesterol gallstone formation in prairie dogs. Science 211: 1429-1432.

12. Smith BF, LaMont JT (1985) Identification of gallbladder mucin-bilirubin complex in human cholesterol gallstone matrix: effects of reducing agents on in vitro dissolution of matrix and intact gallstones. J Clin Invest 76: 439-445.

13. Remaley AT, Rifai N, Warnick GR (2015) Lipids, lipoproteins, apolipoproteins and other cardiac risk factors. In: Burtis CA, Bruns DE, Sawyer BG (Editors) Tietz Fundamentals of Clinical Chemistry and Molecular Diagnostics (7th edn.), Elsevier, Sj Louis, Missouri, USA pp: 388-411.

14. Davidson MH, Ballantyne CM, Jacobson TA, Bittner VA, Braun LT, et al. (2011) Clinical utility of inflammatory markers and advanced lipoprotein testing: advice from an expert panel of lipid specialists. J Clin Lipidol 5: 338-367.

15. Vesper HW, Wilson PW, Rifai N (2012) A message from the laboratory community to the National Cholesterol Education Program Adult Treatment Panel IV. Clin Chem 58: 523-527.

16. Stinton LM, Shaffer EA (2012) Epidemiology of gallbladder disease: Cholelithiasis and cancer. Gut Liver 6: 172-187.

17. Petitti DB, Friedman GD, Klatsky AL (1981) Association of a history of gallbladder disease with a reduced concentration of high-densitylipoprotein cholesterol. N Engl J Med 304: 1396-1398.

18. Ahlberg J (1979) Serum lipid levels and hyperlipoproteinaemia in gallstone patients. Acta Chir Scand 145: 373-377.

19. Sakuta H, Suzuki T (2005) Plasma total homocysteine and gallstone in middle-aged Japanese men. J Gastroenterol 40: 1061-1064.

20. Expert Panel on Detection, Evaluation and Treatment of High Blood Cholesterol in Adults (2001) Executive summary of The Third Report of The National Cholesterol Education Program (NCEP) Expert Panel on Detection, Evaluation, and Treatment of High Blood Cholesterol in adults (Adult Treatment Panel III). JAMA 285: 2486-2497.

21. Eckel RH, Grundy SM, Zimmet PZ (2005) The metabolic syndrome. Lancet 365: 1415-1428.

22. Haq AMM, Giasuddin ASM, Jhuma KA, Choudhury MAM (2016) Effect of cholecystectomy on lipid profile in Bangladeshi patients with cholelithiasis. J Metabolic Synd 5: 1-5.

23. Giasuddin ASM, Jhuma KA, Choudhury MAM, Haq AMM (2016) Lipoprotein (a) status and effect of laparoscopic cholecystectomy on it in Bangladeshi patients with cholelithiasis. J metabolic Synd 5.

24. Kirkwood BR, Sterne JAC (2008). Essential Medical Statistics (2nd edn.) (Reprinted), Oxford: Blackwell Science Ltd.

25. Mendez-Sanchez N, Chavez-Tapia NC, Motola-Kuba D, Sanchez-Lara K, Ponciano-Rodriguez G, et al. (2005) Metabolic syndrome as a risk factor for gallstone disease. World J Gastroenterol 11: 1653-1657.

26. Mendez-Sanchez N, Chavez-Tapia NC, Uribe M (2003) The role of dietary fats in the pathogenesis of gallstones. Front Biosci 8: e420-e427.

27. Expert Panel on Detection, Evaluation, and Treatment of High Blood Cholesterol in Adults (2001) Executive summary of The Third Report of the National Cholesterol Education Program (NCEP) Expert Panel on Detection, Evaluation and Treatment of High Blood Cholesterol in Adults (Adult Treatment Panel III). JAMA 285: 2486-2497.

28. Ata N, Kucukazman M, Yavuz B, Bulus H, Dal K, et al. (2011) The metabolic syndrome is associated with complicated gallstone disease. Can J Gastroenterol 25: 274-276.

29. Portincasa P, Moschetta A, Palasciano G (2006) Cholesterol gallstone disease. Lancet 368: 230-239.

30. Shaffer EA (2005) Epidemiology and risk factors for gallstone disease: has the paradigm changed in the 21st century? Curr Gastroenterol Rep 7: 132-140. 
Citation: Choudhury MAM, Giasuddin ASM, Jhuma KA, Haq AMM (2018) Effects of Laparoscopic Cholecystectomy on Mucin1 and Cholesterol Ester Transfer Protein Status in Bangladeshi patients with Cholelithiasis. J Metabolic Synd 7: 240. doi:10.4172/2167-0943.1000240

Page 5 of 5

31. Ruhl CE, Everhart JE (2000) Association of diabetes, serum insulin, and C-peptide with gallbladder disease. Hepatology 3I: 299-303.

32. Nervi F, Miquel JF, Alvarez M, Ferreccio C, García-Zattera MJ, et al. (2006) Gallbladder disease is associated with insulin resistance in a high risk Hispanic population. J Hepatol 45: 299-305.

33. Biddinger SB, Haas JT, Yu BB, Bezy O, Jing E, et al. (2008) Hepatic insulin resistance directly promotes formation of cholesterol gallstones. Nat Med 14: 778-782.
34. Nakeeb A, Comuzzie AG, Al-Azzawi H, Sonnenberg GE, Kissebah AH, et al. (2006) Insulin resistance causes human gallbladder dysmotility. J Gastrointest Surg. 10: 940-948.

35. Hall JE (Editor) (2013) Guyton \& Hall Textbook of Medical Physiology: A South Asian Edition: Chennai, India: Elsevier Inc. 